\title{
Behaviors of Concern after Acquired Brain Injury: The Role of Negative Emotion Recognition and Anger Misattribution
}

\author{
Lieke S. Jorna ${ }^{1,2, *}$ (1) , Herma J. Westerhof-Evers ${ }^{3}$, Sara Khosdelazad ${ }^{1,2}$, Sandra E. Rakers ${ }^{1,2}$, Joukje van der Naalt ${ }^{2}$, \\ Rob J.M. Groen ${ }^{4}$, Anne M. Buunk ${ }^{1,2}$ and Jacoba M. Spikman ${ }^{1,2}$ \\ ${ }^{1}$ Department of Neurology, Subdepartment of Neuropsychology, University of Groningen, University Medical Center Groningen, Groningen, The Netherlands \\ ${ }^{2}$ Department of Neurology, University of Groningen, University Medical Center Groningen, Groningen, The Netherlands \\ ${ }^{3}$ Department of Rehabilitation, University of Groningen, University Medical Center Groningen, Groningen, The Netherlands \\ ${ }^{4}$ Department of Neurosurgery, University of Groningen, University Medical Center Groningen, Groningen, The Netherlands
}

(Received July 7, 2020; Final Revision December 21, 2020; Accepted December 22, 2020; First Published Online January 14, 2021)

\begin{abstract}
Objective: Behavioral changes are common after acquired brain injury (ABI) and may be caused by social cognition impairments. We investigated whether impaired emotion recognition, specifically Negative Emotion Recognition (NER) and Anger Misattribution (AM), after ABI was related to behavioral problems, so-called Behaviors of Concern (BoC). Method: The study included 139 participants with ABI and 129 healthy controls. BoC was measured using four scales of the Brock Adaptive Functioning Questionnaire (BAFQ): Impulsivity, Aggression, Social Monitoring, and Empathy. Both self-ratings and informant ratings of $\mathrm{BoC}$ were obtained. Emotion recognition was measured with the Ekman 60 Faces Test (FEEST). A NER score was composed of the summed scores on Anger, Disgust, Fear, and Sadness. An AM score was composed of the number of facial expressions wrongly recognized as Anger. Results: Total FEEST scores in ABI participants were significantly worse than in healthy controls. The effect size is moderate. Informants rated significantly more problems in Social Monitoring and Empathy than participants. Effect sizes were small. Scores on FEEST total, NER, and AM were significantly correlated to informant ratings of Social Monitoring. Correlations were weak to moderate. Conclusions: Worse NER and more profound AM were related to more informant-rated problems in social monitoring. In addition, informants rated more problems in social monitoring and empathy than participants. This strongly suggests problems in self-awareness in ABI participants. Consequently, social cognition tests and informant ratings should be used in clinical practice to improve the detection and treatment of BoC after ABI.
\end{abstract}

Keywords: Problem behavior, Social cognition, Emotion recognition, Brain injuries, Subarachnoid hemorrhage, Traumatic brain injury

\section{INTRODUCTION}

Traumatic brain injury (TBI) and subarachnoid hemorrhage (SAH) are serious and sudden injuries to the brain. People who survive these acquired brain injuries (ABI) often encounter long-term cognitive, emotional, and behavioral problems, which can negatively affect daily life functioning, social participation, and quality of life (Al-Khindi et al., 2010; Buunk, Groen, Veenstra, \& Spikman, 2015; De Rooij, Linn, Van Der Plas, Algra, \& Rinkel, 2007; Dikmen, Machamer, Powell, \& Temkin, 2003; Levin, Grossman, Rose, \& Teasdale, 1979).

Behavioral problems are considered especially important in determining the quality of long-term recovery (Brooks, 1990),

*Correspondence and reprint requests to: Lieke Jorna, Department of Neurology (AB51), University Medical Center Groningen, P.O. Box 30.001, 9700 RB Groningen, The Netherlands. E-mail: 1.s.jorna@umcg.nl as they can be severe and persistent (Buunk et al., 2017; Spikman, Timmerman, Coers, \& van der Naalt, 2015). Behavioral problems can have a serious impact on participation: many TBI and SAH patients fail to return to work or to maintain meaningful social relationships (Brooks, Mckinlay, Symington, Beattie, \& Campsie, 1987; Buunk et al., 2015). For relatives of patients, behavioral changes are often a great burden, more than physical or cognitive impairments (Brooks, Campsie, Symington, Beattie, \& McKinlay, 1986; Kinsella, Packer, \& Olver, 1991). Behaviors of Concern $(\mathrm{BoC})$ are those behaviors that have a significant negative impact on the daily functioning and quality of life of individuals and their close relatives (Hicks et al., 2017). Examples of BoC are aggressive behavior, apathy, and sexually inappropriate behavior. Aggression in particular is associated with a greater risk of violent criminality in 
patients with TBI (Williams et al., 2018). BoC was demonstrated in $70.5 \%$ of moderate-severe TBI patients, with verbal aggression and socially inappropriate behavior being most common (Hicks et al., 2017). In a recent study on long-term $\mathrm{BoC}$, mild behavioral disturbances were found in $76 \%$ of TBI patients, while $24 \%$ of patients displayed serious behavioral disturbances (Timmer, Jacobs, Schonherr, Spikman, \& van der Naalt, 2020). In a study by Buchanan, Elias, and Goplen (2000), the majority of SAH patients indicated significant negative behavioral changes. Behavioral changes are often accompanied by impaired self-awareness, which has been demonstrated in both TBI and SAH patients (Buchanan et al., 2000; Hütter \& Kreitschmann-Andermahr, 2014; Spikman \& Van Der Naalt, 2010). For example, ABI patients with behavioral problems rate their social competency significantly better than their relatives (Bach \& David, 2006). Further, TBI patients tend to underreport behavioral difficulties in comparison with physical or cognitive problems (Hart, Sherer, Whyte, Polansky, \& Novack, 2004). This lack of insight limits possibilities to assess the presence and frequency of such problems when only self-report measures are used. The level of self-awareness is unrelated to the severity of brain injury (Bach \& David, 2006).

In recent years, there is increasing evidence that impairments in social cognition are underlying behavioral problems after brain injury (Nijsse, Spikman, Visser-Meily, de Kort, \& van Heugten, 2019; Spikman et al., 2013). Social cognition refers to the cognitive abilities needed to recognize relevant social information, using this to understand the behavior of others and to react appropriately in social situations (Adolphs, 2001; Amodio \& Frith, 2006; Beer, John, Scabini, \& Knight, 2006). Deficits in social cognition have been demonstrated in both TBI and SAH patients (Buunk et al., 2017; McDonald, 2013).

An essential component of social cognition is emotion recognition, which has also shown to be critical for behavior regulation (May et al., 2017; Neumann, Malec, \& Hammond, 2017; Spikman et al., 2013). Previous research demonstrated impaired emotion recognition in TBI and aneurysmal subarachnoid hemorrhage (aSAH) patients as compared to healthy controls (Buunk et al., 2016; Spikman, Timmerman, Milders, Veenstra, \& Van Der Naalt, 2012). A trend toward emotion recognition impairments was also found for angiography-negative subarachnoid hemorrhage (anSAH) patients (Buunk et al., 2016). Specifically, negative facial expressions serve as social reinforcers that condition people to avoid engaging in behaviors that elicit these expressions in others (Hunnikin, Wells, Ash, \& van Goozen, 2020). An inability to recognize negative emotional expressions may, therefore, result in people not adequately adjusting their behavior to other's reactions. This is important to consider since Negative Emotion Recognition (NER) is particularly affected in people with brain injury (Croker \& McDonald, 2005; Hopkins, Dywan, \& Segalowitz, 2002; Radice-Neumann, Zupan, Babbage, \& Willer, 2007; Rapcsak et al., 2000). Additionally, the tendency to falsely perceive negative signals may also result in inappropriate behavior, such as an unwarranted hostile reaction (e.g., starting an argument or verbal or physical aggression). The tendency to make attributions that are significantly more negative than the attributions of the general population is termed negative attribution bias. Negative attribution bias is a clinical problem that has been found in TBI patients (Neumann, Malec, \& Hammond, 2015). A negative attribution bias is also found to be related to interpersonal dysfunction (Carton, Kessler, \& Pape, 1999). Normally, perceiving others' emotional expressions, particularly angry expressions, leads to response reversal (Blair, 2003). Response reversal comprises the modulation of current behavior as a response to observed stimuli. Disruption in this type of reaction, for example, in the form of Anger Misattribution (AM), may lead to problems in modulating behavior based on social cues, which can result in BoC.

The aim of the present study was to investigate whether impaired recognition of negative emotions and AM is related to BoC after TBI and SAH. Additionally, we studied selfawareness in participants to draw conclusions about the reliability of self-ratings. This knowledge is expected to contribute to a better understanding of the nature of $\mathrm{BoC}$ after $\mathrm{ABI}$. Furthermore, it may support the use of emotion recognition tests as instruments that allow timely signaling of patients at risk for behavioral problems.

\section{METHODS}

\section{Participants}

This study included a convenience sample of 139 participants with $\mathrm{ABI}$ (59 patients with TBI and 80 patients with $\mathrm{SAH}$ ) who were included in previous studies. Participants were admitted to the University Medical Center Groningen (UMCG) and were in the chronic phase after injury, with a mean since injury of 5.3 years $(S D=6.2)$. The TBI group consists of participants with moderate-to-severe TBI, classified by a Glasgow Coma Scale (GCS) score below 13 and/or a posttraumatic amnesia duration of at least $24 \mathrm{~h}$. These participants were referred for rehabilitation due to problems in social functioning following TBI. The SAH group consists of participants with both aneurysmal $(n=59)$ and angiographically negative $(n=22) \mathrm{SAH}$. Patients with a traumatic SAH are not included in this group, since they are likely to have additional brain damage. Informants of participants with ABI were also included. Informants generally were family members or close friends of the participants. An informant had to have close and frequent contact with the participant to report on the subject, as judged by the researchers. A total number of 129 healthy participants were included. They had previously been tested for standardization research of the Ekman 60 Faces Test of the Facial Expressions of Emotion - Stimuli and Tests (FEEST) (Young, Perrett, Calder, Sprengelmeyer, \& Ekman, 2002). All participants were aged 18 years or older and had sufficient proficiency in the Dutch language. The study was approved by the Medical Ethical Committee of the UMCG and was conducted in accordance with the Declaration of Helsinki. All participants gave written informed consent. 


\section{Demographic and Neurological Data}

Demographic data (sex, age), time since injury, TBI severity, SAH severity (WFNS; World Federation of Neurological Surgeons; Teasdale et al., 1988), and aneurysm location were obtained from the participants' medical records. TBI severity was dichotomized in moderate (GCS 9-12) and severe TBI (GCS 3-8). For the severity of the clinical condition of SAH participants, WFNS scores 1-3 were classified as "low" and WFNS scores 4-5 were classified as "high". The Dutch Verhage scale was used to classify the level of education, ranging from 1 (no primary school) to 7 (university) (Verhage, 1964). The TBI group consisted of participants with moderate-to-severe TBI, while the SAH group mainly included participants with a low WFNS score. All participants were in the chronic phase after injury, with a mean time since injury of 8.1 years $(S D=8.2)$ in the TBI group and 2.8 years $(S D=.6)$ in the SAH group. Demographic and injury-related characteristics of the TBI group, SAH group, and healthy controls are displayed in Table 1.

\section{Behaviors of Concern}

The Brock Adaptive Functioning Questionnaire (BAFQ) (Dywan \& Segalowitz, 1996) was used to measure BoC, whereby only the subscales that measured $\mathrm{BoC}$ according to the definition of Hicks et al. (2017), namely a behavior that has a significant negative impact on the daily functioning and quality of life of both individuals and their close relatives, were taken into account. This included increased impulsivity and aggression and decreased socially adequate behavior and empathy, measured using four domains of the BAFQ: Impulsivity (seven questions), Aggression (five questions), Social Monitoring (seven questions), and Empathy (five questions). Each question was scored on a scale from 1 (almost never) to 5 (almost always). For Aggression and Empathy, a score of $\geq 11$ indicated problems, while for Impulsivity and Social Monitoring, a score of $\geq 15$ indicated problems. These cutoffs distinguish between people with and without problems. An example question of the Impulsivity scale is "Are you making inappropriate comments or blurting out things you shouldn't have said?", while an example of the Aggression scale is "Are you going to throw things or break things when you're frustrated?". The Social Monitoring scale includes questions such as "Are you a little too close to someone when you are talking to them?" and "Do you not understand jokes or stories that make other people laugh?". Finally, a question of the Empathy scale is: "Would you notice if someone else is feeling exhausted or concerned?". The Social Monitoring and Empathy scales contain mirror items. The internal consistency of the BAFQ is adequate $(\alpha=.92)$. The BAFQ has both a self and an informant version, the latter being filled in by a close relative of the participant. A significant difference between scores on the self and informant version of the BAFQ (with participants reporting lower scores than informants) may be interpreted as an indication of impaired self-awareness of the participant.

\section{Emotion Recognition}

Emotion recognition was measured using the FEEST (Young et al., 2002). In this test, 60 facial expressions of the emotions Anger, Disgust, Fear, Sadness, Happiness, and Surprise are shown, whereby the participant has to select the correct label for the emotion. The total score ranges from 0 to 60 (maximum score of 10 per emotion), with higher scores indicating better emotion recognition. The FEEST is a reliable and valid test for the assessment of emotion recognition (Voncken, Timmerman, Spikman, \& Huitema, 2018; Young et al., 2002). In the current study, scores on the emotions Anger, Disgust, Fear, and Sadness were summed and labeled as NER. The maximum score is 40 . $\mathrm{AM}$ is defined as the number of facial expressions (Disgust, Fear, Sadness, Happiness, and Surprise) wrongly recognized as Anger. The maximum score is 50 .

\section{Statistical Analyses}

Analyses were performed with the Statistical Package for the Social Sciences (SPSS), Version 23.0. Descriptive statistics, including means, standard deviations, and percentages were calculated for participant characteristics. Differences between the (sub)groups were analyzed by means of $t$ tests, Mann-Whitney U tests, and chi-square tests. To analyze associations between BoC, NER, and AM, Spearman correlations were calculated because of the non-normal distribution. An $\alpha$ level of .05 was set for all analyses. Effect sizes were measured using Cohen's d (Cohen, 1988). In the case of multiple comparisons, Holm-Bonferroni corrections were used (Holm, 1979).

\section{RESULTS}

Participants with $\mathrm{ABI}$ and healthy controls were well matched on sex $\left(\chi^{2}=3.193, p=.074\right)$, age $(t=-.79, p=.432)$, and level of education $(t=1.66, p=.10)$. The difference in mean emotion recognition score for men $(M=46.48, S D=5.92)$ and women $(M=48.11, S D=6.17)$ was significant $(t=-2.10$, $p=.037)$. Differences between men and women on NER $(t=-1.71, p=.088)$ and $\mathrm{AM}(t=.27, p=.787)$ were not significant. Table 2 shows that participants with ABI performed significantly worse on overall emotion recognition and NER as compared to healthy controls. The effect sizes were moderate. Participants' scores on recognition of Anger and Fear were also significantly lower than in the control group. The effect sizes were small. We found no differences between SAH and TBI participants in terms of emotion recognition, NER, and AM. For this reason, data for the TBI group and SAH group were taken together for further analyses.

Table 3 displays the percentage of problems and the mean scores on the BAFQ scales, as rated by participants with ABI and informants. For Social Monitoring and Empathy, significant differences were found between the self- and informant ratings, with informants indicating more problems. Effect sizes were small. Spearman correlations between the BAFQ scales were calculated and were all found to be significant $(p<.000)$. 
Table 1. Characteristics of TBI group, SAH group, and controls

\begin{tabular}{|c|c|c|c|c|}
\hline & TBI $(n=59)$ & $\mathrm{SAH}(n=80)$ & Total ABI $(n=139)$ & Controls $(n=129)$ \\
\hline Sex, number of women $(\%)$ & $10(16.9)$ & $50(62.5)$ & $60(43.2)$ & $42(32.6)$ \\
\hline Age in years, $\mathrm{M}(S D)$ & $43.2(13.3)$ & $55.8(10.0)$ & $50.5(13.0)$ & $49.2(13.6)$ \\
\hline Education (Verhage), $\mathrm{M}(S D)$ & $5.0(1.0)$ & $4.8(1.2)$ & $4.9(1.1)$ & $5.1(1.2)$ \\
\hline Time since injury in years, $\mathrm{M}(S D)$ & $8.1(8.2)$ & $2.8(.6)$ & $5.3(6.2)$ & \\
\hline \multicolumn{5}{|l|}{ TBI severity (GCS), (\%) } \\
\hline Moderate & $22(37.3)$ & & & \\
\hline Severe & $37(62.7)$ & & & \\
\hline \multicolumn{5}{|l|}{ SAH severity (WFNS), (\%) } \\
\hline Low & & $66(82.5)$ & & \\
\hline High & & $14(17.5)$ & & \\
\hline
\end{tabular}

TBI, traumatic brain injury; SAH, subarachnoid hemorrhage; ABI, acquired brain injury; GCS, Glasgow Coma Scale; WFNS, World Federation of Neurological Surgeons.

Table 2. Emotion recognition in participants with ABI and healthy controls

\begin{tabular}{|c|c|c|c|c|c|c|c|c|}
\hline & Participants & Controls & & & TBI & SAH & & \\
\hline & $M(S D)(n=139)$ & $M(S D)(n=129)$ & $\mathrm{Z}$ & Cohen's d & $M(S D)(n=59)$ & $M(S D)(n=80)$ & $\mathrm{Z}$ & Cohen's d \\
\hline Anger & $7.5(2.0)$ & $8.2(1.5)$ & $-3.07 *$ & .40 & $6.9(2.1)$ & $7.9(1.8)$ & -2.60 & .51 \\
\hline Fear & $5.6(2.3)$ & $6.4(2.4)$ & $-2.59 *$ & .34 & $5.7(2.4)$ & $5.5(2.3)$ & -.38 & .09 \\
\hline Disgust & $7.1(2.4)$ & $7.8(1.9)$ & -1.83 & .32 & $6.8(2.5)$ & $7.4(2.3)$ & -1.60 & .25 \\
\hline Sadness & $6.7(2.2)$ & $7.3(1.7)$ & -2.22 & .31 & $6.2(2.1)$ & $7.0(2.2)$ & -2.10 & .37 \\
\hline Happiness & $9.8(.6)$ & $9.9(.5)$ & -.66 & .18 & $9.7(.8)$ & $9.9(.4)$ & -.74 & .32 \\
\hline Surprise & $8.7(1.5)$ & $8.9(1.1)$ & -.85 & .15 & $8.6(1.6)$ & $8.7(1.4)$ & -.51 & .07 \\
\hline Total & $45.3(7.2)$ & $48.4(4.7)$ & $-3.28 *$ & .51 & $43.9(7.4)$ & $46.3(6.9)$ & -2.04 & .34 \\
\hline NER & $26.8(6.5)$ & $29.6(4.7)$ & $-3.37 *$ & .49 & $25.6(6.7)$ & $27.8(6.2)$ & -1.87 & .34 \\
\hline $\mathrm{AM}$ & $2.7(2.3)$ & & & & $3.3(2.7)$ & $2.4(2.1)$ & -1.71 & .37 \\
\hline
\end{tabular}

ABI, acquired brain injury; TBI, traumatic brain injury; SAH, subarachnoid hemorrhage; NER, Negative Emotion Recognition; AM, Anger Misattribution. Mann-Whitney U tests were used to compare the results.

*Correlation is significant after Holm-Bonferroni correction.

Spearman correlations for the self-rated scales were Impulsivity -Aggression ( $r=.63)$, Impulsivity-Social Monitoring $(r=.39)$, Impulsivity-Empathy $(r=.31)$, Aggression-Social Monitoring $(r=.30)$, Aggression-Empathy $(r=.31)$, Social Monitoring-Empathy $(r=.61)$. Spearman correlations for the informant-rated scales were: Impulsivity-Aggression $(r=.40)$, Impulsivity-Social Monitoring $(r=.44), \quad$ ImpulsivityEmpathy $(r=.30)$, Aggression-Social Monitoring $(r=.31)$, Aggression-Empathy $\quad(r=.34), \quad$ Social $\quad$ MonitoringEmpathy $(r=.58)$.

Scores on FEEST total, NER, and AM were not related to self-ratings of BoC (Table 4). However, more problems on informant ratings of Social Monitoring were related to significantly lower scores on FEEST total and NER. More problems on informant ratings of Social Monitoring were also related to a significantly higher score on AM. Correlations were weak to moderate in range. Thus, worse NER and more misattributions of anger are related to more problems in Social Monitoring as reported by informants.

\section{DISCUSSION}

The current study investigated the relationship between impaired emotion recognition and $\mathrm{BoC}$ in participants with ABI. Emotion recognition was clearly impaired in participants with $\mathrm{ABI}$ when compared to healthy controls. We were particularly interested in two aspects of emotion recognition: NER and AM. We found a significant relation between one BoC, namely social monitoring, as rated by informants, and these two aspects of emotion recognition. More problems in social monitoring were related to worse NER and more profound AM. No relation with other $\mathrm{BoC}$ was found. In addition, informants rated significantly more social monitoring and empathy problems than participants themselves, suggesting problems in self-awareness in participants with ABI.

In line with previous findings, we found that both TBI and SAH participants performed worse on measures of emotion recognition compared to a group of healthy controls (Buunk et al., 2017; Spikman et al., 2013). Participants scored lower on recognition of Anger and Fear, NER, and overall emotion 
Table 3. Differences in means of self- and informant-rated BoC in participants with ABI

\begin{tabular}{lccrrrr}
\hline \hline & Self $(\%)$ & Informant $(\%)$ & Self $M(S D)$ & Informant $M(S D)$ & $\mathrm{z}$ & Cohen's d \\
\hline Impulsivity & 13.2 & 12.7 & $10.7(3.3)$ & $10.6(3.3)$ & -.80 & .03 \\
Aggression & 13.2 & 11.5 & $8.1(2.7)$ & $7.7(2.4)$ & -1.49 & .16 \\
Social monitoring & 54.4 & 64.2 & $15.4(4.1)$ & $16.7(5.1)$ & $-\mathbf{2 . 6 5} *$ & .28 \\
Empathy & 54.4 & 61.2 & $10.9(3.8)$ & $12.4(5.0)$ & $-\mathbf{3 . 3 0}^{*}$ & .34 \\
\hline \hline
\end{tabular}

$\mathrm{ABI}$, acquired brain injury.

Wilcoxon signed-ranks tests was used to compare the means.

*Difference is significant after Holm-Bonferroni correction.

Table 4. Spearman correlations between BoC, NER, and AM in participants with ABI

\begin{tabular}{|c|c|c|c|c|}
\hline & Impulsivity & Aggression & $\begin{array}{c}\text { Social } \\
\text { Monitoring }\end{array}$ & Empathy \\
\hline \multicolumn{5}{|l|}{ FEEST total } \\
\hline Self & -.01 & .11 & -.10 & -.13 \\
\hline Informant & -.14 & .12 & $-.36 *$ & -.20 \\
\hline \multicolumn{5}{|l|}{ NER } \\
\hline Self & .01 & .10 & -.12 & -.14 \\
\hline Informant & -.11 & .13 & $-.34 *$ & -.17 \\
\hline \multicolumn{5}{|l|}{$\mathrm{AM}$} \\
\hline Self & .12 & .05 & .08 & .16 \\
\hline Informant & .18 & .02 & $.27 *$ & .07 \\
\hline
\end{tabular}

FEEST, Ekman 60 Faces Test of the Facial Expressions of Emotion - Stimuli and Tests; NER, Negative Emotion Recognition; AM, Anger Misattribution; $\mathrm{ABI}$, acquired brain injury.

*Correlation is significant after Holm-Bonferroni correction.

recognition. Participants displayed the lowest scores on fear recognition, but this was also the case for the healthy controls. This finding is in line with previous studies in patients with brain injury, which suggested that the recognition of negative emotions, fear in particular, is especially vulnerable (Croker \& McDonald, 2005; Hopkins et al., 2002; Radice-Neumann et al., 2007; Rapcsak et al., 2000). Additionally, Ietswaart, Milders, Crawford, Currie, and Scott (2008) showed that healthy controls also had more difficulty recognizing negative emotions. Furthermore, when comparing the TBI and SAH groups, we found no differences in emotion recognition, NER, and AM.

This study shows $\mathrm{BoC}$ in a considerable percentage of $\mathrm{SAH}$ and TBI patients, which is in accordance with previous research (Al-Khindi et al., 2010; Hicks et al., 2017; Timmer et al., 2020). Problems in impulsivity and aggression were experienced by $13.2 \%$ of participants, while $54.4 \%$ of participants experienced problems in social monitoring and empathy. Informants observed problems in impulsivity in $12.7 \%$ of participants and problems in aggression in $11.5 \%$ of participants, while problems in social monitoring and empathy were observed more often, in $64.2 \%$ and $61.2 \%$ of participants, respectively. Interestingly, when comparing the mean scores, we found that informants rated significantly more problems in social monitoring and empathy than participants. This difference was not found for the other BoC. In contrast to aggression and impulsivity, problems in social monitoring and empathy can be noticed in a social situation only. This could explain why they are more often noticed by informants. Besides, these problems can also be more subtle than aggressive behavior. However, this does not explain why informants observe significantly more problems in social monitoring and empathy than participants. This difference in observation, together with the fact that NER and $\mathrm{AM}$ were not related to any of the self-reported $\mathrm{BoC}$ measures, suggests problems in self-awareness in patients with ABI. This is not surprising since behavioral changes are often accompanied by impaired self-awareness (Hart et al., 2004; Spikman \& Van Der Naalt, 2010). Impaired self-awareness hampers patients to understand and accept their limitations (Feeney, 2010). This may lead to frustration as they attempt to traverse boundaries they perceive to be unfairly placed upon them, leading to more BoC (Hicks et al., 2017).

Another finding of this study is that impaired emotion recognition and impaired NER were related to the presence of socially inadequate behavior, as rated by informants. The Social Monitoring scale measures to which extent participants are able to detect social cues and adjust their behavior accordingly. Emotions are important social cues, therefore, emotion recognition can be considered a key element in social monitoring (Pickett, Gardner, \& Knowles, 2004). Since we conducted correlation analyses, no causal explanation can be provided. However, because emotion recognition is considered important for intact social behavior and is frequently impaired in TBI and SAH patients, impairments in emotion recognition are expected to underlie problems in social monitoring. This assumption is supported by studies showing a positive effect of emotion recognition training on behavioral problems after ABI (Radice-Neumann, Zupan, Tomita, \& Willer, 2009; Westerhof-Evers et al., 2017).

In addition, AM was also associated with more informantrated problems in social monitoring. This is in line with a study by Cohen, Nienow, Dinzeo, and Docherty (2009), who reported that schizophrenic patients who misinterpret facial emotions as being angry tend to have poorer social functioning than other patients. No associations of NER and AM with aggression, impulsivity, and empathy were found in our study. This is inconsistent with a study by Neumann et al. (2015), which indicated that the more TBI patients perceived other people's behaviors as intentional, hostile, or blameworthy, the more irritated and angry they felt. Even though Neumann et al. (2015) examined judgments of scenarios not facial expressions, it would be expected that the misattribution 
of anger to facial expressions would also be related to irritation and anger and in turn to more aggression. On the other hand, there may be differential contributions of the severity of brain injury and other factors, such as post-traumatic disorder (PTSD), to anger and aggression. Previous research found frontal abnormalities on acute stage CT in moderate-severe TBI patients to be associated with long-term BoC (Spikman et al., 2015). However, anger is also a prominent symptom of PTSD and depression (Besharat, Nia, \& Farahani, 2013; Williamson, Heilman, Porges, Lamb, \& Porges, 2013). Patients with TBI and SAH have a higher risk of both PTSD and depression, which is related to increased aggression (Hedlund, Zetterling, Ronne-Engström, Carlsson, \& Ekselius, 2011; Perroud, Baud, Mouthon, Courtet, \& Malafosse, 2011; Stein et al., 2019; Taft, Creech, \& Murphy, 2017). That aggression is not solely related to the severity and location of brain damage is supported by a recent study of Timmer et al. (2020), who showed that anger (49\%), verbal aggression (11\%), and physically violent behavior (1.9\%) occur in mild TBI patients who have very limited to no brain damage. In comparison, moderate-to-severe TBI patients experienced similar amounts of anger (40\%), verbal aggression (10\%), and physically violent behavior $(.8 \%)$.

Furthermore, a possible reason for not finding stronger associations between NER and AM and other BoC (besides social monitoring) may be the possibly limited validity of the subscales of the BAFQ. The BAFQ only has a few items that address each BoC and may, therefore, not capture them comprehensively. At the same time, the lack of a significant relation between emotion recognition and empathy in our study could be explained by the complexity of the construct empathy. Empathy involves not only a recognition and understanding of another person's emotional state (cognitive component), but also the affective experience of this emotional state (affective component) (Decety \& Jackson, 2004). The BAFQ Empathy scale includes questions that only measure the affective component, thereby assuming the cognitive component is intact. However, understanding of another person's emotional state is crucial for intact empathy and requires intact social cognition.

The main limitation of this study concerns the comparability of the participants. The group of participants with ABI consists of a TBI group and a SAH group that differ in various domains. First, the TBI group only included participants with a relatively severe clinical condition, while the SAH group was more diverse and also included participants with a relatively mild initial clinical condition. Second, the TBI participants were referred for rehabilitation with problems in social functioning, while there was no such selection for the $\mathrm{SAH}$ participants. Since the TBI participants had preexisting problems in social functioning, their performance cannot be generalized to the broader population of persons with moderateto-severe TBI. Third, mean time since brain injury was longer in the TBI group (8.2 years) than in the SAH group (4.8 years). However, recovery of emotion recognition deficits over time is expected to be minimal based on previous research (Ietswaart et al., 2008). Furthermore, groups are trending toward a significant difference in sex distribution. This is a concern knowing that sex does play a role in emotion recognition, with women outperforming men on emotion recognition tasks (Olderbak, Wilhelm, Hildebrandt, \& Quoidbach, 2019; Thompson \& Voyer, 2014). In the current study, women scored significantly higher on general emotion recognition, but not on NER and AM.

Future research should address the reliability and validity of the BAFQ and the use of individual subscales. Besides, more research into the treatment options of $\mathrm{ABI}$ patients displaying $\mathrm{BoC}$ needs to be conducted. Impaired self-awareness is recognized as a limiting factor in functional recovery and rehabilitation outcomes (Prigatano, 1992). It should, therefore, be taken into account in the development of rehabilitation programs for ABI patients displaying BoC. The Treatment for Impairments in Social Cognition and Emotion Regulation (T-ScEmo) was shown to be effective in improving aspects of social cognition, including emotion recognition, as well as proxy-rated empathic behavior in moderate-to-severe TBI patients (Westerhof-Evers et al., 2017). Although the results can only be generalized to patients with moderate-to-severe TBI, it is deemed likely that the findings are replicable in other patient groups with ABI. More research into the effective components and the generalizability of this promising intervention needs to be performed. Another finding of Westerhof-Evers et al. (2017) was that the T-ScEmo group rated the relationship quality with informants to be higher than the control group. Following this finding, it would be interesting to find out whether relationship quality between participant and informant has an effect on the number of BoC reported by informants. To conclude, a history of untreated brain injury predisposes individuals at risk toward delinquent and violent behavior (LeónCarrión \& Ramos, 2003). This suggests that rehabilitation targeted at improving aspects of social cognition and social behavior for ABI patients could also be an effective method for crime prevention.

In conclusion, problems in emotion recognition, specifically impairments in NER and AM, were related to socially inadequate behavior in participants with ABI. Worse NER and a more pronounced AM were only associated with problems in social monitoring according to informant ratings, not with self-rated problems. Combined with the finding that informants rated significantly more problems in social monitoring and empathy, this suggests problems in participants' self-awareness. This highlights the need to use emotion recognition tests and informant ratings in clinical practice to improve the detection and treatment of BoC after ABI.

\section{ACKNOWLEDGMENTS}

There was no financial support for this research.

\section{CONFLICT OF INTEREST}

The authors report no conflicts of interest. 


\section{REFERENCES}

Adolphs, R. (2001, April 1). The neurobiology of social cognition. Current Opinion in Neurobiology, 11(2), 231-239. Elsevier Ltd. doi: 10.1016/S0959-4388(00)00202-6

Al-Khindi, T., Macdonald, R.L., \& Schweizer, T.A. (2010). Cognitive and functional outcome after aneurysmal subarachnoid hemorrhage. Stroke, 41(8), e519-e536. doi: 10.1161/ STROKEAHA. 110.581975

Amodio, D.M. \& Frith, C.D. (2006, March 16). Meeting of minds: the medial frontal cortex and social cognition. Nature Reviews Neuroscience. doi: 10.1038/nrn1884

Bach, L. \& David, A. (2006). Self-Awareness after acquired and traumatic brain injury. Neuropsychological Rehabilitation. doi: 10.1080/09602010500412830

Beer, J.S., John, O.P., Scabini, D., \& Knight, R.T. (2006). Orbitofrontal cortex and social behavior: integrating self-monitoring and emotion-cognition interactions. Journal of Cognitive Neuroscience, 18(6), 871-879. doi: 10.1162/jocn.2006.18.6.871

Besharat, M.A., Nia, M.E., \& Farahani, H. (2013). Anger and major depressive disorder: the mediating role of emotion regulation and anger rumination. Asian Journal of Psychiatry. doi: 10.1016/j.ajp. 2012.07.013

Blair, R.J. (2003). Facial expressions, their communicatory functions and neuro-cognitive substrates. Philosophical transactions of the Royal Society of London. Series B, Biological sciences, 358(1431), 561-572. doi: 10.1098/rstb.2002.1220

Brooks, N. (1990). Behavioural and social consequences of severe head injury. In B. G. Deelman, R. J. Saan, \& A. H. van Zomeren (Eds.), Traumatic brain injury. Clinical, social and rehabilitational aspects (pp. 77-88). Amsterdam: Swets and Zeitlinger.

Brooks, N., Campsie, L., Symington, C., Beattie, A., \& McKinlay, W. (1986). The five year outcome of severe blunt head injury: a relative's view. Journal of Neurology, Neurosurgery and Psychiatry. BMJ Publishing Group. doi: 10.1136/jnnp.49.7.764

Brooks, N., Mckinlay, W., Symington, C., Beattie, A., \& Campsie, L. (1987). Return to work within the first seven years of severe head injury. Brain Injury, 1(1), 5-19. doi: 10.3109/ 02699058709034439

Buchanan, K.M., Elias, L.J., \& Goplen, G.B. (2000). Differing perspectives on outcome after subarachnoid hemorrhage: the patient, the relative, the neurosurgeon. Neurosurgery, 46(4), 831-840. doi: 10.1097/00006123-200004000-00012

Buunk, A.M., Groen, R.J.M., Veenstra, W.S., Metzemaekers, J.D.M., van der Hoeven, J.H., van Dijk, J.M.C., \& Spikman, J.M. (2016). Cognitive deficits after aneurysmal and angiographically negative subarachnoid hemorrhage: memory, attention, executive functioning, and emotion recognition. Neuropsychology. doi: 10.1037/neu0000296

Buunk, A.M., Groen, R.J.M., Veenstra, W.S., \& Spikman, J.M. (2015). Leisure and social participation in patients 4-10 years after aneurysmal subarachnoid haemorrhage. Brain Injury. doi: 10. 3109/02699052.2015.1073789

Buunk, A.M., Spikman, J.M., Veenstra, W.S., van Laar, P.J., Metzemaekers, J.D.M., van Dijk, J.M.C., .. Groen, R.J.M. (2017). Social cognition impairments after aneurysmal subarachnoid haemorrhage: associations with deficits in interpersonal behaviour, apathy, and impaired self-awareness. Neuropsychologia. doi: 10.1016/j.neuropsychologia.2017.07.015

Carton, J.S., Kessler, E.A., \& Pape, C.L. (1999). Nonverbal decoding skills and relationship well-being in adults. Journal of Nonverbal Behavior, 23(1), 91-100. doi: 10.1023/A:1021339410262
Cohen, A.S., Nienow, T.M., Dinzeo, T.J., \& Docherty, N.M. (2009). Attribution biases in schizophrenia: relationship to clinical and functional impairments. Psychopathology, 42(1), 40-46. doi: 10.1159/000173702

Cohen, J. (1988). Statistical Power Analysis for the Behavioral Sciences (2nd ed.). New York, NY: Routledge Academic.

Croker, V. \& McDonald, S. (2005). Recognition of emotion from facial expression following traumatic brain injury. Brain Injury, 19(10), 787-799. doi: 10.1080/02699050500110033

De Rooij, N.K., Linn, F.H.H., Van Der Plas, J.A., Algra, A., \& Rinkel, G.J.E. (2007). Incidence of subarachnoid haemorrhage: A systematic review with emphasis on region, age, gender and time trends. Journal of Neurology, Neurosurgery and Psychiatry, 78(12), 1365-1372. doi: 10.1136/jnnp.2007.117655

Decety, J. \& Jackson, P.L. (2004). The functional architecture of human empathy. Behavioral and Cognitive Neuroscience Reviews. doi: 10.1177/1534582304267187

Dikmen, S.S., Machamer, J.E., Powell, J.M., \& Temkin, N.R. (2003). Outcome 3 to 5 years after moderate to severe traumatic brain injury. Archives of Physical Medicine and Rehabilitation, 84(10), 1449-1457. doi: 10.1016/S0003-9993(03)00287-9

Dywan, J., \& Segalowitz, S.J. (1996). Self- and family ratings of adaptive behavior after traumatic brain injury: Psychometric scores and frontally generated ERPs. Journal of Head Trauma Rehabilitation. doi: 10.1097/00001199-199604000-00008

Feeney, T.J. (2010). There's always something that works: principles and practices of positive support for individuals with traumatic brain injury and problem behaviors. Seminars in Speech and Language, 31(3), 145-161. doi: 10.1055/s-0030-1257531

Hart, T., Sherer, M., Whyte, J., Polansky, M., \& Novack, T.A. (2004). Awareness of behavioral, cognitive, and physical deficits in acute traumatic brain injury. Archives of Physical Medicine and Rehabilitation, 85(9), 1450-1456. doi: 10.1016/j.apmr.2004.01.030

Hedlund, M., Zetterling, M., Ronne-Engström, E., Carlsson, M., \& Ekselius, L. (2011). Depression and post-traumatic stress disorder after aneurysmal subarachnoid haemorrhage in relation to lifetime psychiatric morbidity. British Journal of Neurosurgery, 25(6), 693-700. doi: 10.3109/02688697.2011.578769

Hicks, A.J., Gould, K.R., Hopwood, M., Kenardy, J., Krivonos, I., \& Ponsford, J.L. (2017). Behaviours of concern following moderate to severe traumatic brain injury in individuals living in the community. Brain Injury. doi: 10.1080/02699052.2017.1317361

Holm, S. (1979). A simple sequentially rejective multiple test procedure. Scandinavian Journal of Statistics, 6(2), 65. doi: 10.2307/ 4615733

Hopkins, M.J., Dywan, J., \& Segalowitz, S.J. (2002). Altered electrodermal response to facial expression after closed head injury. Brain Injury, 16(3), 245-257. doi: 10.1080/02699050110103346

Hunnikin, L.M., Wells, A.E., Ash, D.P., \& van Goozen, S.H.M. (2020). The nature and extent of emotion recognition and empathy impairments in children showing disruptive behaviour referred into a crime prevention programme. European Child and Adolescent Psychiatry, 29(3), 363-371. doi: 10.1007/ s00787-019-01358-w

Hütter, B.O. \& Kreitschmann-Andermahr, I. (2014). Subarachnoid hemorrhage as a psychological trauma: Clinical article. Journal of Neurosurgery, 120(4), 923-930. doi: 10.3171/2013.11. JNS121552

Ietswaart, M., Milders, M., Crawford, J.R., Currie, D., \& Scott, C.L. (2008). Longitudinal aspects of emotion recognition in patients with traumatic brain injury. Neuropsychologia, 46(1), 148-159. doi: 10.1016/j.neuropsychologia.2007.08.002 
Kinsella, G., Packer, S., \& Olver, J. (1991). Maternal reporting of behaviour following very severe blunt head injury. Journal of Neurology Neurosurgery and Psychiatry, 54(5), 422-426. doi: 10.1136/jnnp.54.5.422

León-Carrión, J. \& Ramos, F.J.C. (2003). Blows to the head during development can predispose to violent criminal behaviour: rehabilitation of consequences of head injury is a measure for crime prevention. Brain Injury. doi: 10.1080/0269905021000010249

Levin, H.S., Grossman, R.G., Rose, J.E., \& Teasdale, G. (1979). Long-Term neuropsychological outcome of closed head injury. Journal of Neurosurgery, 50(4), 412-422. doi: 10.3171/jns. 1979.50.4.0412

May, M., Milders, M., Downey, B., Whyte, M., Higgins, V., Wojcik, Z., ... O'Rourke, S. (2017). Social behavior and impairments in social cognition following traumatic brain injury. Journal of the International Neuropsychological Society, 23(5), 400-411. doi: 10.1017/S1355617717000182

McDonald, S. (2013). Impairments in social cognition following severe traumatic brain injury. Journal of the International Neuropsychological Society. Cambridge University Press. doi: 10.1017/S1355617712001506

Neumann, D., Malec, J.F., \& Hammond, F.M. (2015). The association of negative attributions with irritation and anger after brain injury. Rehabilitation Psychology, 60(2), 155-161. doi: 10.1037/ rep0000036

Neumann, D., Malec, J.F., \& Hammond, F.M. (2017). Negative attribution bias and anger after traumatic brain injury. Journal of Head Trauma Rehabilitation. doi: 10.1097/HTR. 0000000000000259

Nijsse, B., Spikman, J.M., Visser-Meily, J.M.A., de Kort, P.L.M., \& van Heugten, C.M. (2019). Social cognition impairments are associated with behavioural changes in the long term after stroke. PLoS One, 14(3), 1-15. doi: 10.1371/journal.pone.0213725

Olderbak, S., Wilhelm, O., Hildebrandt, A., \& Quoidbach, J. (2019). Sex differences in facial emotion perception ability across the lifespan. Cognition and Emotion. doi: 10.1080/02699931. 2018.1454403

Perroud, N., Baud, P., Mouthon, D., Courtet, P., \& Malafosse, A. (2011). Impulsivity, aggression and suicidal behavior in unipolar and bipolar disorders. Journal of Affective Disorders, 134(1-3), 112-118. doi: 10.1016/j.jad.2011.05.048

Pickett, C.L., Gardner, W.L., \& Knowles, M. (2004). Getting a cue: the need to belong and enhanced sensitivity to social cues. Personality \& Social Psychology Bulletin, 30(9), 1095-1107. doi: 10.1177/0146167203262085

Prigatano, G.P. (1992). Personality disturbances associated with traumatic brain injury. Journal of Consulting and Clinical Psychology. doi: 10.1037/0022-006X.60.3.360

Radice-Neumann, D., Zupan, B., Babbage, D.R., \& Willer, B. (2007). Overview of impaired facial affect recognition in persons with traumatic brain injury. Brain Injury. Taylor and Francis Ltd. doi: 10.1080/02699050701504281

Radice-Neumann, D., Zupan, B., Tomita, M., \& Willer, B. (2009). Training emotional processing in persons with brain injury. Journal of Head Trauma Rehabilitation, 24(5), 313-323. doi: 10.1097/HTR.0b013e3181b09160

Rapcsak, S.Z., Galper, S.R., Comer, J.F., Reminger, S.L., Nielsen, L., Kaszniak, A.W., ... Cohen, R.A. (2000). Fear recognition deficits after focal brain damage: a cautionary note. Neurology, 54(3), 575-581. doi: 10.1212/wnl.54.3.575
Spikman, J.M., Milders, M.V., Visser-Keizer, A.C., WesterhofEvers, H.J., Herben-Dekker, M., \& van der Naalt, J. (2013). Deficits in facial emotion recognition indicate behavioral changes and impaired self-awareness after moderate to severe traumatic brain injury. PLoS One. doi: 10.1371/journal.pone.0065581

Spikman, J.M., Timmerman, M.E., Coers, A., \& van der Naalt, J. (2015). Early CT frontal abnormalities predict long term neurobehavioral problems but not affective problems after moderate to severe TBI. Journal of Neurotrauma. doi: 10.1089/neu. 2014.3788

Spikman, J.M., Timmerman, M.E., Milders, M.V., Veenstra, W.S., \& Van Der Naalt, J. (2012). Social cognition impairments in relation to general cognitive deficits, injury severity, and prefrontal lesions in traumatic brain injury patients. Journal of Neurotrauma, 29(1), 101-111. doi: 10.1089/neu.2011.2084

Spikman, J.M. \& Van Der Naalt, J. (2010). Indices of impaired selfawareness in traumatic brain injury patients with focal frontal lesions and executive deficits: implications for outcome measurement. Journal of Neurotrauma, 27(7), 1195-1202. doi: 10.1089/ neu. 2010.1277

Stein, M.B., Jain, S., Giacino, J.T., Levin, H., Dikmen, S., Nelson, L.D., .. Z Zafonte, R. (2019). Risk of posttraumatic stress disorder and major depression in civilian patients after mild traumatic brain injury: a TRACK-TBI study. JAMA Psychiatry, 76(3), 249-258. doi: 10.1001/jamapsychiatry.2018.4288

Taft, C.T., Creech, S.K., \& Murphy, C.M. (2017). Anger and aggression in PTSD. Current Opinion in Psychology, 14, 67-71. doi: 10. 1016/j.copsyc.2016.11.008

Teasdale, G.M., Drake, C.G., Hunt, W., Kassell, N., Sano, K., Pertuiset, B., \& De Villiers, J.C. (1988). A universal subarachnoid hemorrhage scale: report of a committee of the world Federation of Neurosurgical Societies. Journal of Neurology, Neurosurgery, and Psychiatry, 51(11), 1457. doi: 10.1136/jnnp.51.11.1457

Thompson, A.E., \& Voyer, D. (2014). Sex differences in the ability to recognise non-verbal displays of emotion: a meta-analysis. Cognition and Emotion. doi: 10.1080/02699931.2013.875889

Timmer, M.L., Jacobs, B., Schonherr, M.C., Spikman, J.M., \& van der Naalt, J. (2020). The spectrum of long-term behavioral disturbances and provided care after traumatic brain injury. Frontiers in Neurology, 11, 1-8. doi: 10.3389/fneur.2020.00246 Verhage, F. (1964). Intelligentie en leeftijd: Onderzoek bij Nederlanders van twaalf tot zevenenzeventig jaar [Intelligence and age: Study on Dutch people from age 12 to 77]. Assen: Van Gorcum: Koninklijke Van Gorcum.

Voncken, L., Timmerman, M.E., Spikman, J.M., \& Huitema, R.B. (2018). Beschrijving van de nieuwe, Nederlandse normering van de Ekman 60 Faces Test (EFT), onderdeel van de FEEST [Description of the new, Dutch norms of the Ekman 60 Faces Test (EFT), part of the FEEST]. Tijdschrift Voor Neuropsychologie, 13(2), 143-151.

Westerhof-Evers, H.J., Visser-Keizer, A.C., Fasotti, L., Schönherr, M.C., Vink, M., Van Der Naalt, J., \& Spikman, J.M. (2017). Effectiveness of a Treatment for Impairments in Social Cognition and Emotion Regulation (T-ScEmo) after traumatic brain injury: a randomized controlled trial. Journal of Head Trauma Rehabilitation. doi: 10.1097/HTR.0000000000000332

Williams, W.H., Chitsabesan, P., Fazel, S., McMillan, T., Hughes, N., Parsonage, M., \& Tonks, J. (2018). Traumatic brain injury: a potential cause of violent crime? The Lancet Psychiatry. doi: 10. 1016/S2215-0366(18)30062-2 
Williamson, J.B., Heilman, K.M., Porges, E.C., Lamb, D.G., \& Porges, S.W. (2013). A possible mechanism for PTSD symptoms in patients with traumatic brain injury: central autonomic network disruption. Frontiers in Neuroengineering. doi: 10.3389/fneng. 2013.00013
Young, A., Perrett, D., Calder, A., Sprengelmeyer, R., \& Ekman, P. (2002). Facial expressions of emotion: Stimuli and tests (FEEST). Thames Valley Test Company, Bury St Edmunds, Edmunds, England. 